\title{
Entre filosofía e historia o filosofía de la historia: una ontología del presente
}

\author{
José Antonio Mateos Castro
}

\begin{abstract}
No hay otra salida para el filósofo, ya que no puede suponer la existencia de ningún propósito racional propio en los hombres y en todo su juego, que tratar de descubrir en este curso contradictorio de las cosas humanas alguna intención de la naturaleza, para que, valiéndose de ella, le sea posible trazar una historia de criaturas semejantes que proceden sin ningún plan propio, conforme, sin embargo, a un determinado plan de la naturaleza.

Immanuel Kant
\end{abstract}

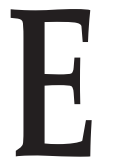

n este texto, pretendemos encontrar y señalar la relación que existe entre la filosofía y la historia y fundamentalmente en Immanuel Kant, ello no quiere decir que sólo entre dichos saberes exista tal relación, por motivos metodológicos nos centraremos sólo en estos dos. Trataremos de encontrar tal relación haciendo un pequeño esbozo histórico desde la Antigüedad clásica griega hasta la Ilustración, mostrando que los dos niveles de reflexión de la filosofía sobre la historia se han tocado y han permanecido siempre unidos, me refiero concretamente a la filosofía critica de la historia y a la filosofía especulativa de la historia. Haremos más explícita y detenidamente esta relación en la filosofía de la historia de Kant, tratando de entender y pensar los objetivos planteados de dicha filosofía en el siglo XVIII, para terminar con algunas consideraciones generales de Michel Foucault con relación a los objetivos planteados.

Es importante comenzar diciendo que la relación entre los distintos saberes es algo evidente, ya que no podemos afirmar de manera categórica que existan estudios puros (históricos, filosóficos, etcétera). Muchas veces, si se quiere alcanzar "rigor" y "objetividad", se necesita de las conclusiones de otras disciplinas, aquellas que permitan y contribuyan al esclarecimiento de los problemas que nos merecen atención, problemas relacionados con el hombre. Esta forma de ver la relación entre los saberes, hace notar una interdisciplinareidad entre ellos y, no excluye, en este caso, a la historia y a la filosofía. 
Dentro de la filosofía, la historia tiende a entenderse en dos sentidos: por un lado, como la ciencia que dirige el conocimiento de los hechos, es decir, aquella que reconstruye científicamente los hechos; por el otro, como la organización de esos hechos conforme a un plan o una idea. A la primera acepción se acerca la filosofía crítica o formal de la historia (las investigaciones, análisis, especulaciones que se ocupan de la naturaleza de la realidad histórica, de las categorías de la historia, independientemente de los hechos concretos); a la segunda, la filosofía especulativa de la historia (investigaciones, análisis y, sobre todo, especulaciones que tienen como objeto a la historia concreta y que aspira a ordenar los hechos).

Ambas formas de acercarse a la historia representan o conforman problemas específicos; en el caso de la filosofía crítica: problemas de tipo ontológico y epistemológicos, ${ }^{1}$ que tienen como objetivo reflexionar sobre la ciencia histórica, preguntando por sus principios, sus fundamentos, sus estructuras y condiciones de validez. Con ello, pretende fundamentar a la historia, respondiendo a argumentos escépticos y mostrando sus condiciones epistémicas necesarias (principios, axiomas, presupuestos), al mismo tiempo que delimita su ámbito en relación con otros saberes.

Por el lado de la filosofía especulativa, fundamentalmente se refiere al sentido de la historia, organizando los hechos conforme a un plan o una idea, presuponiendo una unidad de sentido y un contexto global. En otras palabras, se le considera como un constructo filosófico, como un modo de recordar y organizar los hechos, por lo tanto, no es una teoría científica o epistemológica de la realidad sino la historia que se funda por las ideas, en este caso, filosóficas.

Dentro de la historia de la filosofía podemos encontrar diferentes ejemplos de filosofías especulativas: la historia vista como decadencia (auténtica interpretación histórica de la Antigüedad griega: edades: Hesíodo, Platón, Vico, Fichte, Hegel, Comte), como ciclo (ligada al ciclo del mundo: Anaximandro, Empédocles, Demócrito, Nietzsche, Spengler), como reino del azar (causalidad, fortuna: Aristóteles, Schopenhauer, Maquiavelo), como progreso (medida, norma: Vico, Voltaire, Kant, Hegel) o como orden providencial (necesidad del devenir histórico: orígenes, san Agustín, J. de Fiore). Todo lo anterior presupone que el proceso histórico está basado en un factor capital, en un motor de desarrollo (Dios, conciencia, voluntad, idea, razón), pero, además, en una concepción del tiempo: ya sea un tiempo lineal, en espiral, providencial o cíclico.

\footnotetext{
${ }^{1}$ Ontológicos: ¿qué realidad es la realidad histórica?, ¿en qué se diferencia de la realidad natural?, ¿cuál es la naturaleza de los hechos históricos? Epistemológicos: ¿es el conocimiento histórico un conocimiento de leyes?, ¿es la historia una ciencia social?, ¿qué es la objetividad histórica?, ¿qué es la verdad en historia?, ¿qué es un hecho histórico?, etcétera.
} 
De lo anterior, no se deduce que ambos acercamientos filosóficos estén separados, por el contrario, muchas veces en la historia de la filosofía, una visión especulativa de la historia, es decir, el presupuesto de un motor capital en el proceso histórico y la concepción del tiempo, han llevado a reflexiones epistemológicas y metodológicas. Revisemos esto.

Por ejemplo, en el caso de la filosofía griega, tanto presocrática como clásica, ella se encuentra fundada en una metafísica rigurosamente antihistórica, ya que se considera a la historia como una ciencia del obrar humano que se manifiesta en un mundo cambiante imposible de conocer, debido a que se opone al orden inmutable del cosmos que legisla como canon y esencia del hombre griego: en la política, en el arte, en la tragedia, en la filosofía, etcétera (armonía, perfección). Así lo muestra Parménides el metafísico: "Todo es eterno, algo que existe no puede convertirse en nada. El cambio es imposible... El ser es lo que es, fuera del ser no hay nada". Esta concepción filosófica considera que el mundo perceptible, perecedero y múltiple no es motivo de conocimiento, ya que es un mundo caótico que debe subordinarse a la sabiduría teórica, a un pensamiento lógico que protege contra el cambio y la caducidad, alcanzando así la inmortalidad de los dioses, en consecuencia la historia tendría que ser imposible. Nos dice Platón en el Timeo: "El conocimiento salva, retiene su identidad, imprime en su devenir el carácter de ser". En este mismo sentido nos lo recuerda Aristóteles: "El tiempo está hecho para olvidar [...] El conocimiento procede de lo que no es tiempo: la contemplación”. Bajo estas afirmaciones podemos encontrar la idea de que el tiempo vivido es una potencia negativa, es un tiempo que todo lo devora y es por eso que es un tiempo que infunde temor y que inspira el deseo de salir de él. El ser de Parménides, las ideas de Platón, la sustancia aristotélica, el Dios como motor inmóvil, el concepto de eternidad son ejemplos claros de lo antes dicho.

A pesar de dicha concepción metafísica antihistórica, la tragedia griega (Esquilo, Sófocles y Eurípides) recupera las contradicciones del mundo humano (tekné), del logos humano, afirmándolo y entretejiéndolo con la eternidad de los dioses. "Las técnicas son conquistas de la humanidad", decía Anaxágoras; "El hombre es la medida de todas las cosas", afirmaba Protágoras; "Todo fluye, todo está en movimiento, nada dura eternamente”, filosofaba Heráclito. En suma, consideraban que el tiempo y el movimiento eran la esencia de todas las cosas, el fuego prometeico de la razón técnica que se afirma y se opone al logos y al saber de los dioses, es decir, al logos teórico. Esta actitud desaloja las constantes y seguras permanencias construidas por el pensamiento a las que se aferraban la existencia presa del vértigo y la arroja nuevamente, de manera ineluctable, al tiempo, al mundo y al hombre.

Bajo este contexto, Heródoto narra para siempre hazañas de griegos y bárbaros, observando, investigando relatos de los pueblos y elevándolos a 
una reflexión general, buscando las causas por las que guerreaban. Evitando de este modo, que con el tiempo cayeran en el olvido. Heródoto nos habla del logos que rige los hechos de los hombres rescatándolos del olvido, es el logos de la memoria, que es a la vez, memoria del logos. O como lo expresara Tucídides en la Guerra del Peloponeso: "La historia la hacen los hombres y sólo los hombres con sus capacidades o estupideces" (capacidad humana de creación). De esta manera, si no se logra la certidumbre completa de los acontecimientos humanos, por lo menos la verosimilitud. En este sentido, nuestro autor busca causas humanas conforme a la naturaleza del hombre y causas sociopolíticas de las acciones: periodicidad, regularidad, previsión bajo la pluralidad del acontecer político, la cual sólo se logra analizando la naturaleza humana y haciendo de los acontecimientos humanos producto de la racionalidad que el historiador vuelve inteligibles.

Esta tarea vista desde el cristianismo, la parte especulativa y crítica de la historia, encuadra cronológicamente a la historia, en cálculo de años y periodos, en el dominio de la temporalidad; pasado, presente y futuro se conectan lógica y vitalmente en la tierra (historicidad), cristianizando el devenir humano en un proceso universal, providencial, apocalíptico y unitario, a la vez que consideran, que la vuelta eterna (concepción del tiempo y presupuesto de un motor) es para un mundo sin esperanza "Cristo que ha muerto por nosotros, no muere más". Es así que la venida de Cristo es un acontecimiento central de la historia, señala un antes y un después, desde ésta perspectiva, san Agustín de Hipona, periodiza a la historia en función de la historiografía sagrada, es decir, relaciona el tiempo con la eternidad, afirmando que los hombres son peregrinos, extranjeros hasta el final de los tiempos, cuando Dios separe a las dos ciudades; la ciudad de Dios y la ciudad terrena. De esta forma, él capta el proceso histórico en su conjunto y en su significado más profundo. Ello mostraría que la sustancia de la historia del hombre es un conflicto entre dos ciudades (K. Löwith) que se entremezclan en el mundo terrenal realizando una peregrinación hacia la tierra de promisión o patria celestial. Esta visión escatológica de la historia, supone un plan previo y un telos, donde el pasado es comprendido a partir del futuro que lo ilumina y le da sentido, en otras palabras, es la realización del Plan de Dios para la salvación de la humanidad y, para ello, se tenía que explicar el plan divino en distintas etapas históricas.

Sin embargo, es en el siglo XVIII, cuando la filosofía y la historia se emparentan de manera muy cercana, así lo expresa Carbonell: "...las relaciones que mantienen la historia y la filosofía son el signo del Siglo de las Luces. Relaciones tan íntimas que a veces las dos palabras llegan a ser sinónimas, considerando el mismo tema..."2

\footnotetext{
${ }^{2}$ Charles-Olivier Carbonell, La historiografía. México, FCE, 2001, p. 95.
} 
Dentro de este contexto, se habla del progreso, del espíritu humano, de manera muy reiterada ${ }^{3}$ dentro de la filosofía y la historia. Explicando y jerarquizando causas, extrayendo de causas particulares la causa general de los asuntos humanos (historia filosófica: Montesquieu, E. Gibbon); reflexionando sobre el objeto de la historiografía, sobre su utilidad y sobre la manera de escribir la historia (filosofía sobre la historia: Voltaire, Kant); e interrogándose de manera global sobre la marcha de las sociedades humanas (filosofía de la historia).

Es un marco donde existe una conciencia filosófica, conciencia que refiere a una manera de saber estar en el mundo, a una percepción de capacidades operativas y de posibilidades de emancipación política, pero además, de una conciencia histórica del mundo, de los ánimos humanos que es el mundo civil o mundo de las naciones (sociedad, civilidad, cultura, política). Es una autorreflexión que los hombres hacen y asumen de su tiempo, de su pasado histórico como parte de su horizonte existencial y vivencial. Todo ello presupone dos cosas; un sentido unitario del pasado y un conocimiento científico de la historia, o sea, una filosofía especulativa y una filosofía crítica de la historia.

La historia, dentro de este marco, se entiende como un proceso creador (Vico, Herder, Montesquieu, Hegel), como una realidad cambiante de donde la filosofía emerge, volviendo a ella, a la historia, para comprender su estructura y, al mismo tiempo, comprenderse a sí misma. La filosofía de la historia, a partir de este momento, se convierte en una nueva racionalidad que enfoca de manera distinta las relaciones: del hombre con la naturaleza (progreso científico, matematización de la realidad y apropiación del mundo), del hombre con Dios (Reforma protestante, desteologización de la realidad e historización de la religión) y del hombre consigo mismo (antropologismo, conciencia histórica y filosofía de la historia, creencia en el progreso de la humanidad. La ilustración como actitud intelectual y los ideales, el pensamiento social y político y la fundamentación de la moral). Todo ello presuponiendo una estructura teológica de la historia; lineal, universal y una ley que rige y le da sentido al proceso histórico.

Detengámonos un poco y analicemos detenidamente la relación entre historia y filosofía en Immanuel Kant (racionalista progresista: universalismo racionalista, la filosofía marcha y busca en la historia realidades como razón, progreso, idea, libertad), en su texto Filosofía de la historia, nos muestra una actitud ilustrada, pero además la cercanía y la necesidad de la historia. En el artículo filosófico-político “¿Qué es la Ilustración?” de 1784, desarrolla una con-

${ }^{3}$ Ejemplos claros de ello son: Turgot, Cuadro filosófico de los progresos (1750) y Condorcet, Esbozo de un cuadro histórico de los progresos (1794). 
cepción de la historia, en él podemos encontrar una mirada retrospectiva de los principios de un modo de pensar que comenzó con una revolución en la visión del mundo físico (I. Newton) ${ }^{4}$ y que terminó con la transformación social llamada Revolución francesa.

En Kant, encontramos una consideración de la actualidad histórica en la que se inserta su pensamiento, es decir, la inscripción de las filosofías en el conjunto de conocimientos que constituyen a la cultura moderna. Nuestro filósofo abre un horizonte nuevo, un sistema y un método. Trata de ofrecer al ser humano una responsabilidad acrecentada en cuanto a su propio destino moral y político (autonomía, libertad e igualdad ante la ley). En este artículo, Kant está anunciando un recibimiento cronológico llamado Ilustración, a partir de ese momento nos revela que el pensamiento filosófico no podrá desplegarse en la ignorancia de la historia (posibilidad de transformar el presente y liberarse del pasado). Esta revolución kantiana tiene dos dimensiones: por un lado, la función del ser humano en cuanto a sus posibilidades de su saber y de su acción (problemas que son abordados en la Crítica de la razón pura y en la Critica de la razón práctica), es decir, la razón se interroga a sí misma y trata de establecer las condiciones de validez de su uso; autonomía en el saber, en la moral, bajo un fundamento universal y necesario (para ejercer la crítica es necesario establecer los límites de la razón). En este sentido, Kant retoma las problemáticas de su siglo, cuestionándolas y formulándolas bajo un principio racional, al mismo tiempo que sistematiza los campos del saber. Por el otro, la relación con la historia, su importancia radica en la naturaleza del signo del suceso, en otras palabras, en la legitimación para la filosofía de la pregunta por el presente y de su actualidad histórica.

Por ello, nuestro autor define a la Ilustración de manera negativa, como una salida o un escape que nos libera de cierto status de inmadurez:

La ilustración es la liberación del hombre de su culpable incapacidad. La incapacidad significa la imposibilidad de servirse de su inteligencia sin la guía de otro. Esta incapacidad es culpable porque su causa no reside en la falta de inteligencia sino de decisión y valor para servirse por sí mismo de ella sin la tutela de otro. [...] iTen el valor de servirte de tu propia razón!: he aquí el lema de la ilustración. ${ }^{5}$

${ }^{4}$ El mundo regido por leyes naturales. El conocimiento concebido así, es inmutable. En el caso de Kant, considera que la acciones humanas son producto de la libertad de la voluntad, como si fuera un trozo de naturaleza, reduciéndola a leyes, como el de las órbitas de los planetas (Kepler) o la dinámica (Newton).

${ }^{5}$ Emmanuel Kant, Filosofía de la historia. Trad. y pról. de Eugenio Ímaz, México, FCE, 1987, p. 25. 
Esta liberación o salida, se caracteriza como un fenómeno, un proceso en curso pero también como una tarea y una obligación que implica un cambio interior: "Atreverse a saber", tener el coraje y la audacia de saber. El hombre en este sentido participa colectivamente y se convierte en elemento y agente al mismo tiempo de dicho proceso. Sólo la humanidad alcanzará la madurez cuando no requiera obedecer, sino cuando se le diga: "Obedece y serás capaz de razonar tanto como quieras”. En palabras de Kant:

[...] el uso público de su razón le debe estar permitido a todo el mundo y esto es lo único que puede traer ilustración a los hombres; [...] Entiendo por uso público aquel que, en calidad de maestro, se puede hacer de la propia razón ante el gran público del mundo de lectores. Por uso privado entiendo el que ese mismo personaje puede hacer en su calidad de funcionario. ${ }^{6}$

Es claro que el uso público de la razón, refiere cuando el ser humano se piensa como totalidad, como integrante de la "humanidad", cuando se lleva a cabo un uso universal, libre y público, y no cuando el ser humano es un fragmento particular de la sociedad, o sea, cuando se le considera sólo como una pieza de la gran maquinaria. En consecuencia, para Kant, la Ilustración será el momento histórico en el que la humanidad pondrá su propia razón en uso, sin someterla a la autoridad, entonces será el momento para la crítica, ya que el papel de esta filosofía define las condiciones bajo las cuales el uso de la razón se legitimó para determinar qué es lo que puede saberse, qué es lo que debe hacerse y qué se puede esperar de ello. La crítica, se convierte así en el manual de la razón.

Lo que Kant nos revela es un "signo histórico", donde reconoce la vigencia de un plan de la historia que conduce a una sociedad más racional. Por eso, el pasado es interpretado a la luz de posibilidades emancipatorias que los mismos acontecimientos encierran. Concebidos ellos como parte de un proceso de autosuperación de la naturaleza humana, mediante la creación de instituciones políticas cada vez más racionales. En ese sentido, la historia será el lugar en donde se producirá la ruptura con los lazos de la tradición y la costumbre, mediante un paulatino proceso de reflexión crítica racional, convirtiéndose así la filosofía kantiana en un proyecto histórico, jurídico y filosófico.

En la historia de la humanidad puede verse, según nuestro autor, tanto un espectáculo de crimen organizado y de locura colectiva, como también la lucha por la libertad. Entonces para poder entender a la historia, la clave se

${ }^{6}$ Ibid., p. 28 
encontraría en una teoría de la sociedad y en las formas de Estado que hagan posible la convivencia de la libertad de cada uno con la de los demás. Es decir, se piensa a la historia desde la filosofía práctica, cuyo pilar es la teoría-ética, por eso, la reconstrucción del pasado no se separa de un proyecto de transformación del presente, en este caso, el programa de la Ilustración, que ve una sociedad futura en la que el derecho (legislación) será el único poder sobre la tierra que logre imponer una Paz perpetua (1795), superando el estado de naturaleza y la amenaza permanente de la guerra que hay entre los pueblos, aunque en último término sea ineluctable. En otra palabras, es constituir una paz internacional garantizada institucionalmente.

En el artículo, "Idea de una historia universal en sentido cosmopolita" -interés en las relaciones internacionales- (1784), Kant elabora un modelo teórico que puede servir de hilo conductor para descubrir un sentido histórico, a través de la maraña de los acontecimientos, pero que además le permite reconstruir qué es lo que realmente está pasando en la historia en tanto producto de la acción colectiva de seres humanos, al menos en parte, racionales. La idea de la historia universal, para Kant, es un experimento mental para orientarnos en la historia, pensando en una transición de una forma de sociedad establecida, hacia un mundo en donde se elimine la condición salvaje de los Estados.

En este caso, el hombre juega un papel importante, en él existiría una disposición natural hacia un desarrollo siempre progresivo (racionalidad), pero es un proceso para el que el hombre no está preparado, esta racionalidad se adquiere a través de una experiencia intersubjetiva de socialización y aprendizaje. Este proceso, que es histórico, no es otro que el de la Ilustración (fase civilizatoria por la que debe pasar tanto el individuo como la sociedad, para así poder apropiarse de su razón, de un saber acumulado y elaborado por generaciones). En esa medida, el hombre aparece como un animal para el que no hay un mundo preparado de antemano y, de esta forma, la filosofía se plantea sus tareas históricas y las posibilidades de insertarse en la actualidad, por ello, ella se convertiría en la meta de la historia y en tarea de la Ilustración.

Podemos decir entonces que la filosofía kantiana se convierte en una filosofía que se relaciona con la actualidad histórica, reclamando la libertad individual y el derecho a la igualdad ante la ley. Tratando de incidir en su presente, construyendo un mundo inteligible, donde la razón institucionalice el juego de las fuerzas políticas, económicas y sociales, con base en el libre contrato entre seres iguales. Así, la razón va construyendo a través de la historia el proceso emancipador de la "humanidad". Aunque con la conciencia que este orden ideal está siempre amenazado por la guerra.

Las preguntas y problemas son los siguientes: ¿cómo puede asegurarse el uso público de la razón?, ¿cómo el uso de la razón puede tomar la forma pública que requiere?, ¿cómo la audacia de saber puede ejercerse mientras los 
individuos son obedientes? Kant nos muestra su preocupación histórica por analizar las transformaciones sociales, políticas y culturales de finales del siglo XVIII, y que a pesar de los siglos que nos separan siguen siendo preguntas abiertas y problemáticas en nuestro presente.

Esta tarea histórica-filosófica kantiana es retomada y reconocida abiertamente por Michel Foucault en un texto inédito a propósito del bicentenario de la aparición del artículo de I. Kant ¿Qué es la Ilustración?, que tendría como marco la participación de J. Habermas, Herbert Dreyfus, Richard Rorty y Charles Taylor y que, desgraciadamente la inesperada muerte de M. Foucault (25 de junio de 1984), frustró la realización de este seminario internacional (noviembre de 1984). Aunque posteriormente apareciera la versión del texto que Foucault expondría en tal evento, bajo el nombre de ¿Qué es la Ilustración?, repitiendo el nombre del célebre artículo de Kant.

En el texto de Foucault, podemos encontrar una reflexión sistemática sobre la modernidad y un diagnóstico del subsuelo de nuestro presente (¿qué somos hoy?, ¿en qué consiste este tiempo que estamos viviendo?), es decir, la filosofía vista como un "diagnóstico del presente" en que vivimos y cuya matriz como lo hemos expuesto, es kantiana. En dicho texto se vincula el surgimiento de los problemas específicos de la filosofía moderna a la pregunta kantiana sobre ¿Qué es la Ilustración?, convirtiéndose así en una pregunta por el momento en el que la razón consigue su madurez y por su incidencia en lo que se ha llamado el mundo moderno. A partir de esta pregunta, la filosofía se planteó como indagación en torno a tres manifestaciones de la racionalidad: el pensamiento científico, su manifestación técnica y la organización política. Nos dice Foucault:

Es una reflexión de Kant sobre el status contemporáneo de su propia iniciativa $[. .$.$] me parece que es la primera vez que un filósofo vincula$ de esta manera, estrechamente y desde el interior, el significado de su trabajo con el conocimiento; una reflexión sobre la historia y un análisis particular del momento específico en el cual escribe y por qué lo escribe. Es una reflexión sobre el "presente" como diferencia histórica y como motivo para una particular tarea filosófica lo que a mí me parece tan novedoso. Y me parece, que mirándolo de esta manera, es que podemos reconocer en lo anterior un punto de partida: el perfil de lo que podríamos llamar la actitud de la modernidad. ${ }^{7}$

${ }^{7}$ Michel Foucault, "Reflexiones sobre modernidad y posmodernidad", en Sociológica. Revista de la Universidad Autónoma Metropolitana. Año 3, núm. 7-8, mayodiciembre, 1988. M. Foucault, ¿Qué es la ilustración? Trad. de Rebeca Treviño, pp. 294-295. 
En Foucault, la modernidad no es un tiempo precedido por una época premoderna y sucedida por otra posmoderna, sino una actitud, un modo de relacionarse a la vista de cómo es el tiempo actual o una interrogación filosófica problematizadora del tiempo presente, del modo de cómo nos constituimos como seres históricos y autónomos. En este sentido, el compromiso fijado de Foucault con la Ilustración es una reactivación permanente, una actitud siempre crítica con nuestro ser histórico. Como individuos históricamente determinados por la Ilustración se ha de conocer el proceso histórico de constitución de los límites de nuestra época e intentar su posible liberación, y el ejemplo es Kant (nuestra constitución histórica como sujetos). Como vimos, en Kant se trata de una contestación negativa a la pregunta por la Ilustración: es la salida de un estado de minoría de edad, basado en la tutela religiosa y de la ciencia. Pero abandonadas tales autoridades, se llega al estado de madurez regido por el "Atrévete a saber".

Por una parte, he procurado hacer hincapié en un tipo de pregunta filosófica -que simultáneamente problematiza la relación del hombre con el presente, la forma histórica de ser del hombre y la constitución del yo como un sujeto autónomo- arraigada en la Ilustración. Por otra parte, he intentado insistir en que el hilo que nos puede relacionar con la Ilustración no es aquel que nos ha mantenido fieles a elementos doctrinarios, sino más bien permanente de una actitud; esto es, un ethos filosófico que podría describirse como la crítica permanente de nuestra era. ${ }^{8}$

Foucault considera que el comportamiento crítico de nuestra forma de pensar, decir y actuar se da a través de ciertos rasgos positivos que habrían de conformar una "ontología histórica de nosotros mismos". Por un lado, debido a que considera que el ethos filosófico es una actitud límite y que el conocimiento de los límites nos lleva a sus fronteras. Foucault radicaliza así la actitud kantiana, ahora la crítica no lleva al establecimiento necesario de los límites sino a perseverar en un trabajo indefinido de libertad. Por el otro, el ethos se conforma como una actitud experimental ajena a proyectos globales o radicales. Ahora se materializa en campos particulares como las relaciones familiares, el sexo, la locura o la enfermedad. Esta actitud experimental defendida por Foucault, pretende alcanzar su eficacia a través de una posición desmitificadora de las relaciones de poder; una homogeneidad de actuación materializada en las formas de racionalidad y comportamientos a trans-

${ }^{8}$ Ibid., pp. 297-298. 
formar; una sistematización de objetivos referida a la dirección de las cosas (ciencia), la acción sobre los otros (el poder) y las relaciones consigo mismos (moral); y posee una proyección general en la cultura occidental relacionada con dominios de la experiencia histórica concretos - la locura, el sexo, la enfermedad, el delito. Este ethos crítico guarda en este sentido una importancia ontológica y no doctrinal.

Esto trae consigo una consecuencia obvia: que esa crítica ya no sea practicada en la búsqueda de estructuras formales con valor universal, sino más bien como una investigación histórica de los hechos que nos han conducido a constituirnos a nosotros mismos y a reconocernos como sujetos de lo que hacemos, pensamos y decimos. En este sentido, la crítica no es trascendental y su objeto no es aquel que hace posible a la metafísica. Es genealógico en su diseño y arqueológico en su método. ${ }^{9}$

Arqueológico porque buscará que las instancias del discurso se articulen a lo que pensamos, decimos y hacemos, así como también a los innumerables hechos históricos. Y genealógico en el sentido que se preparará de la contingencia que nos ha hecho ser como somos, a la posibilidad de no serlo más, de pensar y actuar diferente. Es buscar nuevos ímpetus, tanto como sea posible, al indefinido trabajo de la libertad.

La ontología histórica de nosotros mismos, propuesta por Foucault, debe responderse en series abiertas de preguntas; debe interrogarse indefinidamente multiplicándose y especificándose tanto como se quiera, pero dirigiendo sistemáticamente preguntas como las siguientes: ¿cómo nos hemos constituido en sujetos de nuestro propio conocimiento?, ¿cómo nos hemos constituido en sujetos que practican o se someten a las relaciones de poder?, ¿cómo nos hemos constituido en sujetos morales de nuestras propias acciones?, ¿por qué se dan estos límites sociales del comportamiento en que no entro yo?, ¿qué poseo tan extraño que no soy admitido?, ¿qué puedo hacer para ensanchar estos límites y procurar mi reconocimiento? En otras palabras, lo que nuestro autor nos propone, es indagar hasta qué punto conocemos las formas de poder que se practican en determinadas figuras históricas, a través de ciertas formas de problematización que define objetos, reglas de acción, formas de relación consigo mismo. En este sentido, el estudio de los modos de problematización es una manera de analizar preguntas de importancia general en su forma histórica única.

${ }^{9}$ Ibid., pp. 300-301. 
Visto de esta manera, el ejercicio "maduro de la racionalidad crítica" no requiere de un fundamento trascendental sino de un compromiso con el presente, con la actualidad histórica. Un compromiso por el análisis de los límites históricos de la racionalidad, establecidos por ciertas prácticas -cárcel, escuela, fábrica, psiquiátrico-y por el rebasamiento de tales límites por los individuos. Para Foucault, la filosofía en sí misma no tiene una capacidad emancipatoria, más bien, las libertades y los derechos del hombre se fundamentan más en la acción de hombres y mujeres dispuestos a reivindicarlos y defenderlos que en el imperativo kantiano. Él, siempre confió en la propia iniciativa de quienes sufren la explotación o el daño para articular sus luchas. Foucault trata de romper la necesidad de evidencias que oprimen a los individuos mostrando el fondo ridículo, arbitrario, caprichoso en que se asientan nuestras serias y respetables instituciones.

Por todo lo dicho y desde nuestro punto de vista muy particular, la tarea de la filosofía no consistiría más en enunciar la esencia última de las cosas, más bien en indagar las condiciones de posibilidad en que se producen los saberes, la filosofía perdería desde este punto de vista, el status de proyecto fundador y de actividad reflexiva sobre la totalidad, así como Nietzsche la había entendido, como una función parcial, como un diagnóstico del subsuelo de nuestro presente y una mirada más penetrante que descubre bajo la historia del pensamiento, la historia del dolor, de las fuerzas, de las castas, de las deformaciones físicas. En suma, descubrir ese sustrato de fuerzas escondido tras el saber es tarea del "médico filósofo" que rompería con una visión canónica de la realidad.

Sabemos que el discurso filosófico siempre ha roto con los órdenes míticos, con el reino del cielo, de lo que es o debe ser, del destino ineluctable, del reino de los discursos hegemónicos y de ciertos estados de cosas que aparecen y se muestran como inamovibles. Desde esta perspectiva, no sólo se trata de quitar máscaras para encontrar el verdadero ser o "la cosa en sí", sino la de revelar las intenciones ocultas, los juegos estratégicos de poder y de verdad a través de los cuales se ejerce el poder en su faceta de dominio. ${ }^{10}$ Reconocido esto, el filósofo no es más aquel que porta la verdad, sino el que proporciona instrumentos de análisis o un "croquis topográfico" de un estado de cosas que detecte y combata mediante una actividad articuladora. En otras palabras, es sacudir, cuestionar hábitos y formas de actuar y de pensar, disipando familiaridades admitidas.

${ }^{10}$ Ejercer el poder o la voluntad de poder, es desplegar la fuerza propia, es esperar una reacción de nuestra acción, es seguir el instinto. Dominio, por el contrario, implica un estado donde las relaciones de poder no están equilibradas, sino que se ha concentrado en pequeños grupos o individuos. 
Resumiendo, Foucault recupera y somete a lectura el artículo de Kant sobre la Ilustración, porque considera que es un verdadero acontecimiento en el orden del discurso filosófico moderno, a partir del cual se plantea un problema inédito al mismo tiempo que abre un espacio para poner en práctica una forma distinta del pensar crítico. Para él, el texto de Kant trasluce la cuestión del presente como suceso filosófico al que pertenece el filósofo que lo tematiza. Ahí se revela cómo la Ilustración conceptualizada (uso autónomo y legítimo de la razón) aparece también como el umbral de apertura de un tipo de ejercicio crítico en el que está supuesta una actitud, cuyo objeto de reflexión es el estudio del momento en el que se piensa, así como de las posibilidades de inserción en él, para actuar y transformarlo.

Sin embargo, tal vez no se ha alcanzado la mayoría de edad, ya que la Ilustración en sí misma no nos convierte en maduros y tampoco nos lleva ineluctablemente a ella. Aunque podemos decir que la reflexión kantiana es aún una manera vigente de filosofar efectiva después de dos siglos. La crítica al presente, a la actualidad histórica, a nosotros mismos es una actitud donde la crítica a lo que somos es un análisis histórico de los límites que se nos han impuesto y un experimento por transgredirlos o como nos lo dice el mismo Foucault: "No debe decirse, hoy en día, que esta tarea crítica aun ocasiona confianza en la Ilustración; pero sigo pensando que esta tarea requiere trabajar sobre nuestros límites, es decir, una labor paciente proveniente de nuestra impaciencia por la libertad". ${ }^{11}$

${ }^{11}$ M. Foucault, ¿Qué es la ilustración?, p. 304. 
